\title{
COMPARISON OF FETAL OUTCOME IN PLANNED ELECTIVE DELIVERIES AT 38 AND 39 GESTATIONAL WEEKS AT LADY WILLINGDON HOSPITAL, LAHORE
}

\author{
Gul Hani Qaisrani, ${ }^{1}$ Sarwat Rizvi, ${ }^{2}$ Anum Jafri, ${ }^{3}$ Rubar Haider ${ }^{4}$
}

\begin{abstract}
Introduction: Planned elective cesarean delivery is carried out when a patient has no emergency maternal or fetal indication for cesarean section. Such a planned cesarean section can be delayed.

Objective: To compare fetal outcome of planned elective cesarean deliveries at 38 and 39 weeks of gestation in a tertiary care hospital.

Study Design: Cohort Study.

Place and Duration of Study: Lady Willingdon Hospital, Lahore. The study was carried out over a period of six months from 1st October, 2012 to 3st March, 2013.
\end{abstract}

Sample Size: A total number of 470 live born neona-

Qaisrani G.H. ${ }^{1}$

Post Graduate Trainee Dept of Obstetrics \& Gynaecology

Lady Willingdon Hospital, Lahore

\section{Rizvi S. ${ }^{2}$}

Assistant Professor, Dept of Obstetrics \& Gynaecology

KEMU / Lady Willingdon Hospital, Lahore

Jafri A. ${ }^{3}$

Post Graduate Trainee Dept of Pathology

King Edward Medical University, Lahore

Haider R. ${ }^{4}$

$4^{\text {th }}$ Year MBBS Student, King Edward Medical University, Lahore tes were included in the study. 235 neonates were born at 38 weeks while other 235 neonates were born at 39 weeks of gestation.

Results: Majority of patients, 121 (51.48\%) who underwent cesarean section at 38 weeks of gestation were at $26-30$ years of age with mean age of $27.69 \pm$ 3.5 years. Mean parity at 38 weeks cesarean delivery group was $2.4 \pm 1.35 .19(8.1 \%)$ neonates were admitted to intensive care unit in this 38 weeks gestational age cesarean delivery group. Majority of patients 122 $(51.91 \%)$ who underwent cesarean section at 39 weeks of gestation were between $26-30$ years of age with a mean age of $27.36 \pm 3.54$ years. Mean parity of patients in this group was $2.30 \pm 1.280 .6(2.6 \%)$ neonates delivered at 39 weeks of gestation were admitted to neonatal intensive care unit.

Conclusion: Neonatal outcome was better at 39 weeks of gestation as compared to 38 weeks of gestation.

Key Words: Planned cesarean delivery, neonatal intensive care unit admission (NICU), transient tachypnea of newborn.

\section{Introduction}

The first cesarean with a lower segment transverse incision on uterus, also called 'Modern Cesarean,' was carried out in 1881 by a German gynecologist Ferdinand Adolf Keher. ${ }^{1}$ Cesarean section has been cited a number of times from Greek mythology. In the begin- 
ning of $16^{\text {th }}$ century, cesarean section was carried out only when a mother was on her death bed or already dead. With the passage of time, there has been a great deal of improvement in this procedure. ${ }^{2}$ The incidence of caesarean section in Pakistan is almost $13.62 \%$ of the total deliveries, out of which frequency of repeat caesarean section is $29.87 \% .^{3}$ Among full term infants, born prior to 39 gestational weeks, an increased morbidity and mortality during neonatal period and decreesed cognitive abilities in childhood are found. ${ }^{4}$ The timing of caesarean delivery plays an important role in determining clinical outcome of the neonate. ${ }^{5}$ Since there is an increase in rate of repeat cesarean deliveries, it necessitates that there should be appropriate timing of delivery to optimize neonatal outcome. ${ }^{6}$

The American College of Obstetricians and Gynecologists recommends that no elective delivery should be performed before the gestational age of 39 weeks. $^{7}$ Infants who are born before 39 weeks of gestation have an increased risk of neonatal adverse respiratory outcome, e.g. transient tachypnea of newborn ${ }^{5}$ and risk of neonatal intensive care unit admission. ${ }^{8}$ This risk of NICU further increases with decline of gestational age. For this reason, gestational age should be accurately measured. ${ }^{7}$ Most of the admissions to new born special care unit are low birth weight and premature infants. But early term infants also suffer increased morbidity as compared to infants born at or after 39 weeks of gestation. $^{9}$

Among all the deliveries, $84 \%$ are at 37 weeks or greater gestation. Of these, approximately $44 \%$ are planned elective deliveries, i.e. elective inductions or cesarean sections (primary or elective repeat). Clark SL et al 2008, studied neonatal and maternal outcomes with elective delivery at 38 and 39 weeks of gestation. $8 \%$ of fetuses delivered electively at 38 weeks, required neonatal intensive care unit admission for an average of 4.5 days as compared to $2.80 \%$ admissions of infants born at or beyond 39 weeks. ${ }^{9,10}$ Hence there is clear association between elective cesarean delivery at 39 gestational weeks and delivery of healthy fetus, thereby reducing perinatal mortality. ${ }^{3}$ Therefore planing the birth timing should be an important decision and benefits and risks of early delivery associated neonatal morbidity should be thoroughly assessed. ${ }^{12}$ The risks to the neonate posed by cesarean section include Respiratory distress syndrome, Transient tachypnea of newborn, delayed neurologic adaptation, trauma, delay in bonding of mother with neonate, Neonatal intensive care unit admission, persistent pulmonary hypertension and neonatal mortality. ${ }^{13,14}$
Term gestation has been divided in to early term and full term. Early term corresponds to 37 - 38 weeks gestation while full term means gestation including $39-41+6$ weeks. Early term gestation carries more risk of respiratory morbidity as transient tachypnea of newborn and neonatal intensive care unit admission. Earlier the delivery is performed; greater is the risk. ${ }^{5,15,16}$ Arm F. et al in 2010 emphasized that early term birth should be paid great attention because it poses risks to neonate as compared to newborns who deliver later in gestation. ${ }^{17}$

1n 2011, a retrospective cross sectional study was carried out in Shalamar Hospital, Lahore over a period of 7 months. 100 patients were selected who underwent elective cesarean section. It was found that $47 \%$ cesareans were performed at 38 weeks and $9 \%$ at 39 gestational weeks. Amongst babies who were born at 38 weeks, $6.3 \%$ were admitted to neonatology unit out of which $4.2 \%$ had respiratory distress. None of the babies born at 39 weeks were admitted in neonatology unit. Authors concluded that there is a relationship of timing of cesarean and neonatal out come. So, elective cesareans should be delayed up to 39 weeks of gestation. ${ }^{18}$ There are various reasons due to which caesarean sections are performed prior to 38 weeks such as to avoid mother's morbidity associated with an emergency procedure if she gets in to labor ${ }^{19}$ or reluctance of mother to further continue her pregnancy. ${ }^{20}$

This study has been designed in order to limit the burden of costs of long stay in hospitals for unhealthy babies. It will assess the association between delivery at 38 and 39 weeks and the risk of adverse neonatal outcome in terms of neonatal intensive care unit admissions at these gestational ages. The objective of this study is to compare fetal outcome of elective caesarean deliveries at 38 and 39 weeks of gestation in a tertiary care hospital.

\section{Methodology}

A cohort study was carried out in the department of Obstetrics and Gynaecology, Lady Willingdon Hospital, Lahore from $1^{\text {st }}$ October, 2012 to $31^{\text {st }}$ March, 2013. Pregnant females from different parts of Punjab presenting to unit II of Lady Willingdon Hospital for elective caesarean section, who were at 38 or $39^{\text {th }}$ week of gestation were included in the study. Patients with major medical disorders like hypertension (B.P. 140/90 $\mathrm{mm} \mathrm{Hg}$ ) and diabetes (GTT diagnostic), intrauterine growth retarded fetuses diagnosed on Doppler 
ultrasound, RH incompatibility having positive indirect Coombs test and oligohydraminos (AFI < 8) were excluded from the study. 470 neonates were included in the study. Data was stratified in 2 groups, one comprising of the neonates born at 38 weeks and the other included neonates born at 39 weeks of gestation via elective cesarean section. The sample size of 470 cases (235 in each group) was calculated with $80 \%$ power of test, 5\% level of significance and taking expected percentage of NICU admission in both groups i.e. $8 \%$ in 38 weeks group versus $2.80 \%$ in 39 weeks gestational age group in pregnant patients undergoing elective cesarean section. Sampling technique was non probability purposive sampling.

Data was collected by taking informed consent and approval by ethical committee of Lady Willingdon Hospital. Patients were admitted through Out Patient Department and entered into study through specially designed Proforma after taking informed consent. These patients undergoing elective cesarean section were divided into 2 groups according to gestational amenorrhea. Group A represented patients at 38 weeks and group B represented patients at 39 weeks of gestation. In each group patient's demographic details like patient name, age, parity, LMP, history of previous caesarean section were recorded. These neonates were followed after caesarean section to see the fetal outcome in terms of neonatal intensive care unit admission.

The information were analyzed in SPSS version 20. The quantitative variables analyzed were included demographic characteristics like age; parity; presented as mean $\pm \mathrm{SD}$. The qualitative variables i.e. neonatal intensive care unit admission was presented as frequency and percentage with respect to respective gestational ages. Relative risk was calculated to see association between the elective cesarean delivery at 38 and 39 weeks of gestation with neonatal intensive care unit admission. RR > 2 was considered as statistically significant.

\section{Results}

Total 470 cases were included during the study period of six months from October $1^{\text {st }}, 2012$ to March $31^{\text {st }}$, 2013; in the department of Obstetrics and Gynecology, Lady Willingdon Hospital, Lahore. 235 neonates born at 38 weeks of gestation were placed in the first group. In second group, 235 neonates born at 39 weeks of gestation were included.

At 38 weeks of gestation, majority of patients 121
$(51.48 \%)$ were between $26-30$ years of age and there were no patients in age range of $36-40$ years with mean age of $27.69 \pm 3.5$ years (Table 1 ). Patients having cesarean section at 38 weeks of gestation had mean parity of $2.4 \pm 1.35$ (Table 2). Among 235 patients, 19 (8.1\%) neonates were admitted to intensive care unit when cesarean section was performed at 38 weeks of gestation (Table 3). At 39 weeks of gestation, majority of patients $122(51.91 \%)$ were between 26 - 30 years of age and minimum patients $1(0.42 \%)$ were at $36-$ 40 years of age with a mean age of $27.36 \pm 3.54$ years (Table 4). Patients having cesarean section at 39 weeks of gestation had mean parity of $2.30 \pm 1.280$ (Table 5). Among 235 patients having cesarean section performed at 39 weeks of gestation, $6(2.6 \%)$ neonates were admitted to intensive care unit (Table 6). Relative risk

Table 1: Distribution of Cases by Age presenting at 38 Weeks of Gestation.

\begin{tabular}{|c|c|c|}
\hline Age (Year) & $\begin{array}{c}\text { Number of } \\
\text { Patients }\end{array}$ & Percentage \\
\hline $15-20$ & 5 & 2.12 \\
\hline $21-25$ & 70 & 29.78 \\
\hline $26-30$ & 121 & 51.48 \\
\hline $31-35$ & 39 & 16.59 \\
\hline $35-40$ & 0 & 0 \\
\hline Mean & & 27.6936 \\
\hline Std. Deviation & & \pm 3.57217 \\
\hline
\end{tabular}

Table 2: Statistics of Parity of Patients presenting at 38 Weeks of Gestation.

\begin{tabular}{|l|c|}
\hline Parity $(\mathrm{N})$ & 235 \\
\hline Mean & 2.4426 \\
\hline Standard Deviation & \pm 1.35554 \\
\hline
\end{tabular}

Table 3: NICU Admissions at 38 Weeks of Gestation.

\begin{tabular}{|c|c|c|c|c|c|}
\hline & Frequency & Percent & $\begin{array}{l}\text { Valid } \\
\text { Percent }\end{array}$ & $\begin{array}{c}\text { Cumulative } \\
\text { Percent }\end{array}$ \\
\hline \multirow{3}{*}{$\frac{\overline{7}}{7}$} & No & 216 & 91.9 & 91.9 & 91.9 \\
\hline & Yes & 19 & 8.1 & 8.1 & 100.0 \\
\hline & Total & 235 & 100.0 & 100.0 & \\
\hline
\end{tabular}


Table 4: Distribution of Cases by Age presenting at 39 Weeks of Gestation.

\begin{tabular}{|c|c|c|}
\hline Age (Year) & Number of Patients & Percentage \\
\hline $15-20$ & 3 & 1.27 \\
\hline $21-25$ & 65 & 27.31 \\
\hline $26-30$ & 122 & 51.91 \\
\hline $31-35$ & 44 & 18.72 \\
\hline $36-40$ & 1 & 0.42 \\
\hline Mean & & 27.3660 \\
\hline Std. Deviation & & \pm 3.54370 \\
\hline
\end{tabular}

Table 5: Statistics for Parity of Patients presenting at 39 Weeks of Gestation.

\begin{tabular}{|l|c|}
\hline Parity $(\mathrm{N})$ & 235 \\
\hline Mean & 2.3021 \\
\hline Standard Deviation & \pm 1.28027 \\
\hline
\end{tabular}

Table 6: NICU Admission at 39 Weeks of Gestation.

\begin{tabular}{|c|c|c|c|c|c|}
\hline & Frequency & Percent & $\begin{array}{c}\text { Valid } \\
\text { Percent }\end{array}$ & $\begin{array}{c}\text { Cumulative } \\
\text { Percent }\end{array}$ \\
\hline \multirow{3}{*}{$\frac{\pi}{\pi}$} & No & 229 & 97.4 & 97.4 & 97.4 \\
\hline & Yes & 6 & 2.6 & 2.6 & 100.0 \\
\hline & Total & 235 & 100.0 & 100.0 & \\
\hline
\end{tabular}

Table 7: Relative Risk.

\begin{tabular}{|l|c|c|}
\hline & $\begin{array}{c}\text { NICU } \\
\text { Admission }\end{array}$ & $\begin{array}{c}\text { No NICU } \\
\text { Admission }\end{array}$ \\
\hline 38 Weeks of Gestation & $19(\mathrm{a})$ & $216(\mathrm{~b})$ \\
\hline 39 Weeks of Gestation & $6(\mathrm{c})$ & $229(\mathrm{~d})$ \\
\hline
\end{tabular}

of neonatal intensive care unit admission at 38 weeks compared to 39 weeks was found to be 3.16 which are significant (Table 7).

Relative risk of NICU admission if babies are born by elective cesarean section at 38 weeks of gestation is calculated as:

$\mathrm{RR}=(\mathrm{a} / \mathrm{a}+\mathrm{b}) /(\mathrm{c} / \mathrm{c}+\mathrm{d})$
$R R=0.08085 / 0.02553$

$\mathrm{RR}=3.16686$

\section{Discussion}

The risk of neonatal intensive care unit admission after elective cesarean section was increased three fold at 38 weeks of gestation as compared to 39 weeks of gestation at Lady Willingdon Hospital Lahore, between 1st October 2012 and $31^{\text {st }}$ March 2013. The relative risk of neonatal intensive care unit admission at 38 weeks of gestation was 3.168 as compared to intensive care unit admission in planned elective cesarean section at 39 weeks of gestation. It is statistically significant. In our study $19(8.1 \%)$ of neonates were admitted to intensive care unit after they were born by planned elective cesarean section at 38 weeks of gestation.

A previous prospective observational study was conducted in 27 hospitals by Clark SL et al in 2009. It compared neonatal and maternal outcomes after elective term cesarean deliveries. Authors noticed that $8 \%$ of neonates were admitted to intensive care unit when delivered at $38-39$ weeks of gestation. ${ }^{9}$ Our study results are comparable to the study result performed by Clark SL et al in 2009.

Similarly, a prospective cohort study was performed by Tita ATN et al from 1999 to 2000 . There was $8.1 \%$ of neonatal intensive care unit admission at 38 weeks of gestation in planned elective cesarean deliveries. ${ }^{5}$ This study result is also comparable to our study.

In our study, 6 (2.6\%) of infants delivered by planned elective cesarean delivery at 39 weeks of gestation required intensive care unit admission. In 2007, Tracy SK et al in their study reported $2.80 \%$ of neonatal admissions to intensive care unit when delivered by elective cesarean section at 39 weeks of gestation. ${ }^{10}$ Our study results at this gestation are comparable to this study. In other studies, gestational age was not handled as a separate entity. Neonatal outcome at each gestation was not noted. And they handled gestational age as a potential confounder.

According to the study carried out by Tutdibi et al, even at full term gestation i.e. 39 weeks, there were neonatal admissions to intensive care unit. It was found that major cause of neonatal admission to nursery was transient tachypnea of newborn after planned elective cesarean section in a patient having no other risk factors. This risk increased as the gestational age of delivery decreased even at term i.e. 38 weeks of gestation. $^{20}$ 
Our study supports that with the decreasing gestational age, there is an increase in neonatal intensive care unit admission. The neonatal intensive care unit admission decreased by just waiting for one week i.e. 39 weeks of gestation. So, this information should be considered both by women who are planning for elective cesarean section and by the physicians who are involved in counseling such patients.

\section{Conclusion}

Elective cesarean section at 38 weeks of gestation increased neonatal intensive care unit admission (NI$\mathrm{CU})$ threefold. There was a reduction in neonatal intensive care unit admission when neonates were born at 39 weeks of gestation. But there was not the complete absence of neonatal admission at 39 weeks of gestation. So, plan elective cesarean sections at 39 weeks of gestation in low risk women in order to reduce complications at early term gestation, nursery admissions, their cost and many more procedures on neonate.

\section{References}

1. Cesarean section. Accessed at Wikipedia - the free Encyclopedia, May 09, 2013.

2. Doherty EG, Eichenwald EC. Cesarean delivery: emphasis on the neonate. Clin Obstet Gynecol. 2004; 47 (2): 332-341.

3. Qazi R, Akhtar S. Obstetrical correlates of the first time cesarean section compared with the repeated cesarean section. JCPSP. 2007; 17 (10): 611-4.

4. Davis EP, Claudia BL, Muftler T, Head K, Hasso A, Wing DA et al. children's brain development benefits from longer gestation. Frontiers in psychology, 2011; 2: 1-7. E.pub 09 February.

5. Tita AT, Landon MB, Spong CY, Lai Y, Leveno KJ, Varner MW, Moawad AH, Caritis SN, Meis PJ, WApner RJ, Sorokin Y, Miodovnik M, Carpetner M, Peaceman AM, O'Sullivan MJ, Sibai BM, Langer O, Thorp JM, Ramin SM, Mercer BM for the Eunice Kennedy Shriver NICHD Maternal - Fetal Medicine Units Network. Timing of Elective Repeat Cesarean Delivery at Term and Neonatal Outcomes. N Engl J Med. 2009; 360 (2): 111-20.

6. Tuuli MG, Odibo AO. Neonatal outcomes in relation to timing of repeat cesarean delivery at term. Women's health, 2009; 5 (3): 239-42.
7. Ashton DM. elective delivery at less than 39 weeks. Curr Opin Obs and Gnecol. 2010; 22: 506-10.

8. Hoffmire CA, Chess PR, Ben Saad T, Glantz JC. Elective delivery before 39 weeks: the risk of infant admission to the neonatal intensive care unit. Maternal and child health journal, 2010; 16 (5): 1053-62.

9. Clark SL, Miller DD, Belfort MA, Dildy GA, Frye DK, Meyers JA. Neonatal and maternal outcomes associated with elective term delivery. Am J Obstet Gynecol. 2009; 200: 156.e1-156.e4.

10. Tracy S, Tracy M, Sullivan E. Admission of term infants to neonatal intensive care: A population-based study. J Women's health Nursing and Midwifery, 2007; 34 (4): 301-7.

11. Ehrenthal DB, Hoffman MK, Jiang X, Ostrum G. Neonatal outcomes after implementation of guidelines limiting elective delivery before 39 weeks of gestation. Obstetrics and Gynecology, 2011; 118 (5): 1047-55.

12. Hansen AK, Wisborg K, Uldbjerg N, Brink Henriksen $\mathrm{T}$. Risk of respiratory morbidity in term infants delivered by elective caesarean section: cohort study. BMJ. 2008; 336 (7635): 85-87.

13. Demers A. should patients be entitled to cesarean section on demand? Canadian Family Physician, 2011; 57: 1247-8

14. Nicoll AE, Black C, Powls A, F. M. An audit of neonatal respiratory morbidity following elective cesarean section at term. SMJ. 2003; 49 (1): 22-5.

15. White E, Shy KK, Daling JR. An investigation of the relationship between cesarean section birth and respiratory distress syndrome of the newborn. American Journal of Epidemiology, 1985; 121 (5): 651-63.

16. Arm F, Oinuma M, Clak SI. Rethinking the definition of "Term Pregnancy". Obstet Gynecol. 2011; 116: 1369.

17. Dar RL, Sohail S, S. R. Appropriate gestational age for elective C-section. Biomedica, 2012; 28: 46-8.

18. Wilmink FA, Hukkelhoven CW, Lunshof S, Mol BW, van der Post JA, Papatsonis DN. Neonatal outcome following elective cesarean section beyond 37 weeks of gestation: a 7 - year retrospective analysis of a national registry. Am J Obstet Gynecol. 2010; 202 (3): 250 e1-8.

19. Halliday HL. Elective delivery at "term": implications for the newborn. Acta Paediatr. 1999; 88: 1180-1183.

20. Tutdibi E, Gries K, Biicheler M, Misselwitz B, Sehlosser RL, Gortner L. Impact of labor on outcomes in transient tachypnea of the newborn: Population - based study, 2010. 